\title{
Current challenges facing junior doctors in the NHS: a quantitative survey
}

\author{
Authors: J Tweedie, Y Goh, C Postlethwaite, M Choudry, G Cantelo, J Dacre and A Goddard
}

\section{Introduction}

Once a highly competitive specialty, competition rates (CR) for core medical training (CMT) have been falling since 2013. Based on CR (number of applicants received per advertised post), CMT ranked 14th out of 16 specialties in 2016. We sought to further understand and provide evidence for the endemic roots of low morale among all grades of junior doctors.

\section{Aim}

To describe and provide evidence for the current challenges facing junior doctors working in the NHS.

\section{Methods}

Junior doctor members of the RCP $(n=2,033)$ were emailed a questionnaire link, with a cover letter explaining the goals of the study. Additionally, the link to the questionnaire was promoted through social media (Twitter), with a direct link to the survey.

\section{Results}

Descriptive

In total, 498 junior doctors completed the survey.

Patient safety

Respondents identified poor availability of out-of-hospital care as the factor with the most serious impact on patient safety. $61 \%$ of respondents reported this as having a serious or extremely serious impact on patient care.

\section{Impact on mental and physical health}

$18 \%$ of respondents reported that their physical health is often adversely affected by their job (Fig 3). 25\% of respondents reported that their mental health is often adversely affected by their job (Fig 3).

\section{Feeling valued}

$7.8 \%$ of trainees reported feeling often or extremely valued by the chief executive of their hospital or trust. $6.7 \%$ of trainees felt often or extremely valued by their non-clinical managers. $99.2 \%$ of junior doctors felt valued by the trainees that they supervise and $96.1 \%$ felt valued by patients.

\section{Discussion}

Current working pressures and patterns are having a profound effect on the physical and mental health of junior doctors, some of whom are only at the very beginning of their career.

\section{Conclusion}

If the NHS is to attract and maintain the best staff to care for its patients, urgent steps need to be taken to value, support and motivate the junior doctors who work within it. 